(C) 2015 Metaphilosophy LLC and John Wiley \& Sons Ltd

METAPHILOSOPHY

Vol. 46, Nos. 4-5, October 2015

0026-1068

\title{
THE PROBLEM OF NECESSARY AND SUFFICIENT CONDITIONS AND CONCEPTUAL ANALYSIS
}

\author{
MICHAEL J. SHAFFER
}

\begin{abstract}
In this article the standard philosophical method involving intuitiondriven conceptual analysis is challenged in a new way. This orthodox approach to philosophy takes analysanda to be the specifications of the content of concepts in the form of sets of necessary and sufficient conditions. Here it is argued that there is no adequate account of what necessary and sufficient conditions are. So, the targets of applications of the standard philosophical method so understood are not sufficiently well understood for this method to be dependable.
\end{abstract}

Keywords: conceptual analysis, intuition, methodology, necessary condition, philosophy, sufficient condition.

One prominent account of the methods of philosophy is that philosophy is intuition-driven conceptual analysis. In fact, according to a significant number of philosophers, such conceptual analysis is the only method of philosophy. For the purposes at hand, this account of the methods of philosophy will be referred to as the standard philosophical method (SPM). This methodological account of philosophy can be more completely characterized as follows:

(1) Conceptual analyses take the form of proposed definitions (that is, sets of necessary and sufficient conditions) or analysanda.

(2) The adequacy of any anaysandum can be tested against concrete and/or imagined cases.

(3) Whether or not a proposed analysandum is adequate or not with respect to a given case can be determined by the use of a priori intuition, and a priori intuition is a distinct, reliable, and fallible non-sensory mental faculty.

(4) Intuition allows us to reliably access knowledge about concepts.

(5) The method of reflective equilibrium is the particular method by which intuitions can be used to confirm/disconfirm analysanda. ${ }^{1}$

${ }^{1}$ Recent defenses of SPM include Jackson 1998, Bealer 1996, and McGinn 2012. For closely related views see Braddon-Mitchell and Nola 2009. Shaffer forthcoming includes extensive discussion of this view. 
According to the defenders of SPM, this is essentially the method of philosophy in a nutshell, and it has been assumed to be adequate for the solution of philosophical problems by a significant number of both practicing and prominent philosophers throughout the history of philosophy. For example, this is essentially the contention made by Colin McGinn in his recent book Truth by Analysis (2012). McGinn is not in the least bit tentative in his blanket defense of SPM as the one and only method of philosophy. With this aim in mind, early in the book he makes the following extended declaration about philosophy: "[I]t is not a species of empirical enquiry, and it is not methodologically comparable to the natural sciences (though it is comparable to the formal sciences). It seeks the discovery of essences. It operates 'from the armchair': that is, by unaided (usually solitary) contemplation. Its only experiments are thought-experiments, and its data are possibilities (or 'intuitions' about possibilities). Thus philosophy seeks a priori knowledge of objective being - of non-linguistic and non-conceptual reality. We are investigating being as such, but we do so using only a priori methods" (McGinn 2012, 4).

As should be immediately apparent, this is a clear, straightforward, and ringing endorsement of SPM as it has been explicated here. To buttress this contention we need only take note of McGinn's other claims that "the proper method for uncovering the essence of things is precisely conceptual analysis" $(2012,4)$ and that "philosophy, correctly conceived, simply is conceptual analysis" $(2012,11)$. McGinn explains that conceptual analyses then take the form of specifications of the content of a pre-theoretical concept (the analysans) by the articulation of sets of necessary and sufficient conditions (the analysandum). In effect, he believes that we arrive at such analyses by considering possible cases and asking ourselves whether the concept applies or does not apply in those cases - that is by consulting our "intuitions" about such cases $(2012,7)$. What is also important for the purposes at hand is his acknowledgment that this account of philosophical methodology "was really the standard conception for most of the history of the subject, in one form or another" $(2012,7)$. So, not only does McGinn endorse SPM as the sole methodology of contemporary philosophy, he also claims that it is the enduring methodology of philosophical inquiry throughout its history. ${ }^{2}$

One important thing that needs to be clarified about McGinn's version of SPM concerns the nature of the object of analysis (the analysans) and, more important, the nature of the analysandum itself as they are typically understood (that is, as definitions of a particular sort). Carl Hempel usefully makes a crucial distinction in this regard that we can use to illuminate the standard view of such definitions as follows: "The word

${ }^{2}$ See McGinn 2012, 4-11, for a summary identification of significant historical examples of the use of SPM, including some of those already discussed here in more detail. 
'definition' has come to be used in several different senses.... A real definition is conceived of as a statement of the 'essential characteristics' of some entity, as when man is defined as a rational animal or a chair as a separate moveable seat for one person. A nominal definition, on the other hand, is a convention which merely introduces an alternative - and usually abbreviated - notation for a given linguistic expression, in the manner of a stipulation" (Hempel 1952, 2). Moreover, in discussing one proposed definition of a living organism offered by Hutchinson, Hempel tells us further that some real definitions are to be understood as follows: "The expression on the right-hand of (3.2) [that is, the left component of the relevant bi-conditional, $D x \& M x \& R x]$ might be claimed to be synonymous with the phrase ' $\mathrm{x}$ is a living organism' [i.e., $L x]$. In this case, the 'real' definition (3.2) purports to characterize the meaning of the term 'living organism'; it constitutes what we shall call a meaning analysis, or an analytic definition, of that term (or, in an alternative locution, of the concept of a living organism). Its validation requires solely a reflection upon the meanings of its constituent expressions and no empirical investigation of the characteristics of living organisms" $(1952,8) .^{3}$

This is, of course, precisely what McGinn has in mind with respect to conceptual analysis. It is then worth making the obvious point that conceptual analysis is the operation of analyzing concepts via proposing definitions, but to point that out is not enough to fully grasp the view. It is true that SPM is a method that takes as inputs our concepts, but it involves the recognition that the definitions involved are to be understood as meaning analyses rather than some other kind of real definitions. Hempel explains the distinction between these types of definition as follows: "On the other hand, the 'real' definition (3.2) might be intended to assert, not that the phrase ' $x$ is a living organism' has the same meaning as the expression on the right [of the bi-conditional], but rather that, as a matter of empirical fact, the three conditions $D, M$, and $R$ are satisfied simultaneously by those and only those objects which are also living things. The sentence (3.2) would then be an empirical law, and its validation would require reference to empirical evidence concerning the characteristics of those beings. In this case, (3.2) represents what we shall call an empirical analysis of the property of being a living organism" $(1952,8)$. Hempel continues and makes the following crucial point about empirical analysis as distinct from meaning analysis: "Empirical analysis and meaning analysis differ from each other and from nominal definition. Empirical analysis is concerned not with linguistic expressions and their meaning but with empirical phenomena: it states characteristics which are, as a matter of empirical

\footnotetext{
${ }^{3}$ My bracketed notes added. Definition (3.2) has the form $L x \equiv D x \& M x \& R x$. Here $D x$ means " $x$ is a kind of discrete mass that interacts with its environment," $M x$ means " $x$ is a metabolic entity of a particular sort," and $R x$ means " $x$ is an entity that reproduces in a specific manner." See Hempel 1952, 7, for more details.
} 
fact, both necessary and sufficient for the realization of the phenomena under analysis. ... Empirical analysis in terms of general laws is a special case of scientific explanation" (1952, 8-9).

Hempel contrasts this account of empirical analysis with meaning analysis as follows: "Nominal definition and meaning analysis, on the other hand, deal with the meanings of linguistic expressions. But whereas a nominal definition introduces a "new" expression and gives it meaning by stipulation, an analytic definition is concerned with an expression which is already in use-let us call it the analysandum expression or, briefly, the analysandum - and makes its meaning explicit by providing a synonymous expression, the analysans, which of course has to be previously understood" $(1952,9)$. So, for example, the question of whether knowledge is justified true belief is just the question of the analysis of the concept of knowledge in terms of definitions constituted by sets of necessary and sufficient conditions understood as a meaning analysis. Conceptual analysis is then a method of doing something with concepts that we already possess - wherever they have ultimately come from. It is defining a pre-theoretical concept by offering a synonymous expression. It then appears to be the case that the defenders of SPM must believe that concepts have the forms of sets of necessary and sufficient conditions, that such analyses are meaning analyses and that analyses of our pre-analytic concepts are informative. Typical analysanda are thus kinds of decompositions of pre-analytic concepts. They are conceptual truths with the forms of analytic definitions.

Of course, this view is not at all unique to McGinn; many others share this view of conceptual analysis. For example, Robert Audi offers the following like-minded characterization of conceptual analysis: "Let us simply construe it as an attempt to provide an illuminating set of necessary and sufficient conditions for the (correct) application of a concept, where an illuminating set is roughly one which brings out the content or structure of the concept in such a way as to clarify the concept and indicate its relation to at least some other concepts, most typically those representing its constituents" (Audi 1983, 90). ${ }^{4}$ So-for McGinn and other like-minded thinkers - one might think that an analysandum will have the following very simple logical form (where $\mathrm{n}$ is finite): $\left(\mathrm{C} x \equiv\left\{\mathrm{D}_{1} x, \mathrm{D}_{2} x, \mathrm{D}_{3} x, \ldots\right.\right.$, $\left.\left.\mathrm{D}_{\mathrm{n}} x\right\}\right)$. This is supposed then to tell us the true nature or essence of objects of type Cx in terms of a finite set of defining essential features. So, providing such an analysis involves decomposing the analysans into a list of features, thus exposing - in some important sense - the content of the concept. In this article this view will be challenged, but in a new manner. Many recent critics have attacked SPM in terms of points (2) to (5) listed above by challenging the bona fides of the faculty of intuition. This is the 2009 .

${ }^{4}$ See also Hansson 2006, White 1975, Jackson 1998, and Braddon-Mitchell and Nola 
main line of criticism against SPM offered by many defenders of experimental philosophy. Some critics, however, have attacked (1) as well on the basis of the theory of concepts it assumes, but these sorts of criticisms have been less in vogue recently. ${ }^{5}$ Here a new attack on (1) will be mounted. The gist of the criticism is that SPM wrongly assumes that we possess an adequate understanding of the concepts of necessary and sufficient conditions. This criticism stems from the truth of a particular theorem of classical logic.

To this end, the following formula is a, perhaps little appreciated, theorem of classical propositional logic (CPL):

(T) $(\mathrm{p} \rightarrow \mathrm{q}) \vee(\mathrm{q} \rightarrow \mathrm{p})$.

The following simple indirect proof establishes that this is the case:

1. $\neg[(\mathrm{p} \rightarrow \mathrm{q}) \vee(\mathrm{q} \rightarrow \mathrm{p})]$. Assumption.

2. $\neg(\mathrm{p} \rightarrow \mathrm{q}) \& \neg(\mathrm{q} \rightarrow \mathrm{p})$. De Morgan's Theorem, 1 .

3. $\neg \neg(\mathrm{p} \& \neg \mathrm{q}) \& \neg \neg(\mathrm{q} \& \neg \mathrm{p})$. Def. Material Implication (twice), 2.

4. (p \& $\neg \mathrm{q}) \&(\mathrm{q} \& \neg$ p). Double Negation (twice), 3 .

5. (p \& $\neg$ q). Simplification, 3 .

6. (q \& $\neg$ p). Simplification, 3 .

7. p. Simplification, 5 .

8. $\neg$ p. Simplification, 6 .

9. $(\mathrm{p} \& \neg \mathrm{p})$. Conjunction, 7 and 8.

10. $\neg \neg[(p \rightarrow q) \vee(q \rightarrow p)]$. Indirect Proof, $1-9$.

11. $(\mathrm{p} \rightarrow \mathrm{q}) \vee(\mathrm{q} \rightarrow \mathrm{p})$. Double Negation, 10 .

This proof seems to be totally unobjectionable in CPL. However, consider the following two canonical definitions, where $S(p, q)$ means " $p$ is a sufficient condition for q" and $\mathrm{N}(\mathrm{q}, \mathrm{p})$ means "q is a necessary condition for p":

(D1) $(\mathrm{p} \rightarrow \mathrm{q}) \equiv \mathrm{S}(\mathrm{p}, \mathrm{q})$.

(D2) $(\mathrm{p} \rightarrow \mathrm{q}) \equiv \mathrm{N}(\mathrm{q}, \mathrm{p})$.

D1 and D2 are then supposed to be the standard (that is, canonical) interpretations of our ordinary language concepts of necessary and sufficient conditions in CPL. ${ }^{6} \mathrm{D} 1, \mathrm{D} 2$, and T trivially imply then the following statement:

\footnotetext{
${ }^{5}$ See, e.g., Moore 1968 (1942) and Wittgenstein 1953. Moore's paradox of analysis appears to show that such analyses are uninformative, and Wittgenstein claims that concepts have the form of family resemblances rather than sets of necessary and sufficient conditions.

${ }^{6}$ See, e.g., Copi, Cohen, and Flage 2007, 196, 449, and 446, and Fisher 2001, 241.
} 
(S1) $[S(p, q) \& N(q, p)] \vee[S(q, p) \& N(p, q)]$.

As T is a theorem and D1 and D2 are definitions in CPL, this should hold for all $\mathrm{p}$ and $\mathrm{q}$. Consider the following two true English statements:

(E) Earth is a planet.

(N) Electrons have a negative charge.

We know that neither of the following statements is true:

(S2) Earth's being a planet is a sufficient condition for electrons' having a negative charge, and electrons' having a negative charge is a necessary condition for Earth's being a planet.

(S3) Electrons' having a negative charge is a sufficient condition for Earth's being a planet, and Earth's being a planet is a necessary condition for electrons' having a negative charge.

Both S2 and S3 are known to be false as a matter of our background knowledge of the facts involved, and so the disjunction $\mathrm{S} 2 \vee \mathrm{S} 3$ is false. Thus, $\mathrm{S} 1$ is false according to our background knowledge. It does not hold for some pairs of statements. But, the set $\{\mathrm{D} 1, \mathrm{D} 2, \mathrm{~T}\}$ implies that $\mathrm{S} 1$ is true. So, when $\mathrm{E}$ and $\mathrm{N}$ are substituted into $\mathrm{S} 1$ we get a contradiction (and there will be arbitrarily many such contradictions generated for each pair of true sentences that are unrelated in the way that $\mathrm{E}$ and $\mathrm{N}$ are). So, the set $\{\mathrm{D} 1, \mathrm{D} 2, \mathrm{~T}\}$ formally constitutes a paradox.

As Olin (2003) points out, the basic nature of a paradox is that it involves a set of propositions $\Lambda$ each of which is prima facie reasonable to endorse, but where (in the context of background knowledge $\Sigma$ ) the set $\Lambda$ appears to imply a contradiction. So paradoxes are essentially sets of propositions which appear to be individually rationally endorsable but which cannot collectively be endorsed. This can be because the set $\Lambda$ is itself internally inconsistent or because $\Lambda$ appears to imply some proposition $p$ and $\Sigma$ implies $\neg p$. Let us refer to a given set $\Lambda_{\mathrm{i}}$ as the paradox constituting propositions of paradox $i$. We can then also present paradoxes as deductive arguments where the members $\lambda_{1}, \lambda_{2}, \ldots, \lambda_{\mathrm{n}}$ of a given set $\Lambda$ are the premises and where they either appear to directly imply $(p \& \neg p)$ or where $\Lambda$ appears to imply $p$ and $\Sigma$ implies $\neg p$. So in this case \{D1, D2, $\mathrm{T}\}$ is a paradox with respect to $\Sigma$ because $\Sigma$ implies $\neg \mathrm{S} 1$, whereas $\{\mathrm{D} 1, \mathrm{D} 2$, T implies S1. S1 is supposed to be true for all p and q, but we know that this is not the case. As a result, something has gone wrong, and in order to resolve the paradox something has to be given up. ${ }^{7}$ The proof of T seems unobjectionable, however, and so thereby does T. The falsity of both S2 and S3 that grounds the denial of S1 also seems unobjectionable. Some

${ }^{7}$ See Rescher 2001 and Olin 2003 for discussion of paradox resolution. 
pairs of propositions just do not satisfy S1. This leaves only D1 and D2 as the culprits, and it seems to be the case that the canonical concepts of necessary and sufficient conditions are incorrect.

We appear then to need to replace the canonical definitions of necessary and sufficient conditions with some stronger conceptions that do not fall prey to this problem. The immediately obvious suggestion is the idea that there is some modal content in the notion of necessary and sufficient conditions that is left out in D1 and D2, and this suggestion is the one that McGinn and other defenders of SPM appear as if they would endorse. McGinn himself asserts that "modality is central to philosophical investigation - as is definition. The natural and mathematical sciences may also be in the business of discovering essences (chemistry, geometry), but they are not concerned, as sciences, with the modality of what they discover" $(2014,4)$. George Bealer also endorses this form of SPM wholeheartedly and supports the same sort of view when he claims that "the central questions of philosophy - and their answers - are phrased in quite general terms without any mention of particular individuals, species, and so forth. These questions are necessary in the sense that they call for answers that hold necessarily. In being interested in such things as the nature of mind, intelligence, the virtues, and life, philosophers do not want to know what these things just happen to be, but rather what those things must be, what they are in a strong sense" (Bealer 1998, 203-4). ${ }^{8}$

Given this sort of view, analysanda would have the following generic form (where $\mathrm{n}$ is finite): $\square\left(\mathrm{C} x \equiv\left\{\mathrm{D}_{1} x, \mathrm{D}_{2} x, \mathrm{D}_{3} x, \ldots, \mathrm{D}_{\mathrm{n}} x\right\}\right)$. As a result, one could replace D1 and D2 with the following "modalized" definitions of necessary and sufficient conditions:

$\left(D 1^{\prime}\right) \square(p \rightarrow q) \equiv S(p, q)$.

$\left(\mathrm{D} 2^{\prime}\right) \square(\mathrm{p} \rightarrow \mathrm{q}) \equiv \mathrm{N}(\mathrm{q}, \mathrm{p})$.

This substitution appears to resolve the paradox constructed above, but it does so only at the price of introducing an equally unpalatable problem. This is the case because $\mathrm{D}^{\prime}$ and $\mathrm{D} 2^{\prime}$ give rise to the following objectionable kinds of cases. Let $\mathrm{p}$ be any set of contradictory sentences and $\mathrm{q}$ an arbitrary proposition. According to $\mathrm{D}^{\prime}$ and $\mathrm{D} 2^{\prime}$, $\mathrm{p}$ will be a sufficient condition for $\mathrm{q}$ and $\mathrm{q}$ will be a necessary condition for $\mathrm{p}$. This is because of the infamous principle of CPL known as ex contradictione (sequitur) quodlibet. It is another surprising theorem of classical logic, and its proof is quite simple:

1. (p \& $\neg$ p). Assumption.

2. p. Conjunction elimination, 1.

3. $\neg$ p. Conjunction elimination, 1 .

4. $\mathrm{p} \vee \mathrm{q}$. Disjunction introduction, 2.

${ }^{8}$ See Bealer 1998, 201-40, and Bealer 1996, 121-42. 
5. q. Disjunctive syllogism, 3,4 .

$\therefore(\mathrm{p} \& \neg \mathrm{p}) \rightarrow \mathrm{q}$. Conditional proof, $1-5$.

Of course, this generalizes for any q whatsoever, and so every contradiction validly implies every proposition in the context of CPL. This effectively means that if we substitute D1' for D1 and D2' for D2 (in order to avoid the paradox introduced earlier), the defenders of this version of SPM are committed to the view that at every possible world for every q, q has every contradiction as a sufficient condition and $q$ is a necessary condition for every contradiction. This is obviously unacceptable, and so this most obvious attempt to avoid the paradox noted above fails. It appears to be the case that $\mathrm{D}^{\prime}$ and $\mathrm{D} 2^{\prime}$ are equally problematic. So, ultimately, it is not at all clear how exactly we are supposed to define necessary and sufficient conditions, and this is a serious problem for SPM. One might be tempted to appeal to the concept of analyticity, but as should be apparent to everyone at this juncture, any such appeal is bound to be at best controversial in light of the well-known problems with that concept. ${ }^{9}$ Another possible suggestion is to replace the material conditional in D1 and D2 (or in their modalized counterparts) with some form of relevant implication, but that concept is also deeply controversial. ${ }^{10}$

It is not, however, the purpose of this article to resolve this issue; but the fact that we lack an adequate account of necessary and sufficient conditions is a serious and pressing matter once we recognize that the very concept of intensional definition is at stake here, in addition to the more specific recognition that the account of the nature of the targets of conceptual analysis assumes is problematic. This is because the more fundamental canonical account of an intensional definition on which (1) is based is a set of necessary and sufficient conditions, and both the standard account of necessary and sufficient conditions and its modalized relative are inadequate for the reasons raised here.

Department of Philosophy (CH365N)

St. Cloud State University

720 4th Ave. South

St. Cloud, MN 56301

USA

shaffermphil@hotmail.com

\section{References}

Audi, Robert. 1983. "The Applications of Conceptual Analysis." Metaphilosophy 14:87-105.

${ }^{9}$ See Quine 1953, Fodor 1998, and Williamson 2007, chaps. 3 and 4.

${ }^{10}$ See Mares and Meyer 2001 and Nolt 1997, 439-47. 
Bealer, George. 1996. "A Priori Knowledge and the Scope of Philosophy." Philosophical Studies 81:121-42. . 1998. "Intuition and the Autonomy of Philosophy." In Rethinking Intuition, edited by Michael Depaul and William Ramsey, 201-40. New York: Rowman and Littlefield.

Braddon-Mitchell, David, and Robert Nola. 2009. Conceptual Analysis and Philosophical Naturalism. Cambridge, Mass.: MIT Press.

Copi, Irving, Carl Cohen, and Daniel Flage. 2007. Essentials of Logic. 2nd edition. Upper Saddle River, N.J.: Pearson Prentice-Hall.

Fisher, Alec. 2001. Critical Thinking. Cambridge: Cambridge University Press.

Fodor, Jerry. 1998. Concepts. Oxford: Oxford University Press.

Hansson, Sven. 2006. "How to Define: A Tutorial." Princípios 13:5-30.

Hempel, Carl. 1952. Fundamentals of Concept Formation in Empirical Science. Chicago: University of Chicago Press.

Jackson, Frank. 1998. From Metaphysics to Ethics: A Defense of Conceptual Analysis. Oxford: Oxford University Press.

Mares, Edwin, and Robert Meyer. 2001. "Relevant Logics." In The Blackwell Guide to Philosophical Logic, edited by Lou Goble, 280-308. Oxford: Blackwell.

McGinn, Colin. 2012. Truth by Analysis. Oxford: Oxford University Press.

Moore, G. E. 1968. "A Reply to My Critics," § 11: "Analysis." In The Philosophy of G. E. Moore, 3rd edition, edited by Paul Schilpp, 660-67. La Salle, Ill.: Open Court.

Nolt, John. 1997. Logics. Albany, N.Y.: Wadsworth.

Olin, Doris. 2003. Paradox. Montreal: McGill-Queen's University Press.

Quine, W. V. O. 1953. "Two Dogmas of Empiricism.” In From a Logical Point of View, 20-64. New York: Harper and Row.

Rescher, Nicholas. 2001. Paradoxes. Chicago: Open Court.

Shaffer, Michael J. Forthcoming. The Experimental Turn and the Methods of Philosophy. London: Routledge.

White, Alan. 1975. "Conceptual Analysis." In The Owl of Minerva, edited by Charles Bontempo and S. Odell, 103-17. New York: McGraw-Hill. Williamson, Timothy. 2007. The Philosophy of Philosophy. Oxford: Blackwell.

Wittgenstein, Ludwig. 1953. Philosophical Investigations. Translated by G. E. M. Anscombe. New York: Macmillan. 